\title{
Avaliação de uma Nova Abordagem para o Ensino de Química
}

\author{
CHAGAS, Júnior Olair ${ }^{1}$ \\ LOBO, Fabiana Aparecida² \\ GONÇALVES, José Luiz
}

\section{RESUMO}

Neste trabalho é relatado o processo de elaboração e aplicação de um roteiro de atividade prática para professores do ensino médio como uma forma de estratégia didática para o ensino da teoria cinética dos gases na disciplina de química. Esta estratégia foi caracterizada por uma abordagem específica, aula expositiva do conteúdo seguida do vídeo experimental para a discussão do tópico. Optou-se por utilizar o Youtube por ser uma das plataformas mais acessadas por qualquer estudante. Escolheu-se um vídeo que continha um experimento claro e objetivo correlacionado com o conteúdo acima citado. Em seguida, elaborou-se o vídeo da aula prática que conteve com uma breve contextualização no cotidiano dos alunos, seguida do vídeo experimental do Youtube e por fim algumas perguntas discursivas. Os resultados indicam que a abordagem do vídeo experimental apresenta uma vantagem significativa sobre as aulas teóricas, reforçando a importância da utilização de práticas experimentais extras na sala.

Ensino de Química. Aula prática. Teoria dos gases. Termodinâmica. Vídeo experimental.

\section{Appraisal of a new approach to chemistry teaching}

\section{ABSTRACT}

In this work, the process of elaborating and applying a script of practical activity for high school teachers is reported as a form of didactic strategy for teaching the

\footnotetext{
${ }^{1}$ Mestre em Química Analítica pela Universidade Federal de Ouro Preto (UFOP). Doutorando em química inorgânica pela Universidade Federal Fluminense. E-mail: chagasojunior@gmail.com. Lattes: http://lattes.cnpq.br/6820007363922220. Orcid: http://orcid.org/0000-0003-0798-6143.

${ }^{2}$ Doutora em Química Analítica pela Universidade Estadual Paulista Júlio de Mesquita Filho. Professora adjunta da Universidade Federal de Ouro Preto no departamento de Química. Email: fabiana@iceb.ufop.br. Lattes: http://lattes.cnpq.br/1558911369265865. Orcid: http://orcid.org/0000-0001-6808-9679.

${ }^{3}$ Doutor em Engenharia Mecânica e Mestre em Materiais para Engenharia pela Universidade Federal de Itajubá (UNIFEI). Professor substituto no Instituto Federal de Minas Gerais (IFMG). E-mail: jose.luiz@ifmg.edu.br. Lattes: http://lattes.cnpq.br/4443102810983746. Orcid: https://orcid.org/0000-0001-8876-7529.
} 
kinetic theory of gases in the discipline of chemistry. This strategy was characterized by a specific approach, expository class of content followed by the experimental video for the discussion of the topic. We decided to use YouTube as it is one of the most online video-sharing platform accessed by any student. $A$ video was chosen which contained a clear and objective experiment correlated with the above-mentioned content. Then, the video of practical class was elaborated, which contained a brief contextualization in the students' daily lives, followed by experimental YouTube video and finally some discursive questions. The results indicate that the experimental video approach has significant advantage over the analytical classes, reinforcing the importance of using extra experimental practices in classroom.

Chemistry teaching. Practical class. Gas theory. Thermodynamics.

Experimental vídeo.

\section{Evaluación de un nuevo enfoque para la enseñanza de la química}

\section{RESUMEN}

En este trabajo se reporta el proceso de elaboración y aplicación de un guión de actividad práctica para profesores de secundaria como una forma de estrategia didáctica para la enseñanza de la teoría cinética de los gases en la asignatura de la química. Esta estrategia se caracterizó por un enfoque específico, una clase expositiva del contenido seguida del video experimental para la discusión del tema. Optamos por utilizar Youtube ya que es una de las plataformas más visitadas por cualquier estudiante. Se eligió un video que contenía un experimento claro y objetivo correlacionado con el contenido mencionado anteriormente. Luego, se elaboró el video de la clase práctica, que contenía una breve contextualización en la vida cotidiana de los estudiantes, seguido del video experimental de YouTube y finalmente algunas preguntas discursivas. Los resultados indican que el enfoque de video experimental presenta una ventaja significativa sobre las clases teóricas, lo que refuerza la importancia de utilizar prácticas experimentales adicionales en el aula.

Enseñanza de la Química. Clase práctica. Teoría de los gases. Termodinámica. Video experimental.

\section{Valutazione di un nuovo approccio all'insegnamento della chimica}

\section{SOMMARIO}

In questo lavoro viene riportato il processo di elaborazione e applicazione di uno script di attività pratica per insegnanti di scuola secondaria come una forma di strategia didattica per l'insegnamento della teoria cinetica dei gas in materia di chimica. Questa strategia è stata caratterizzata da un approccio specifico, una classe espositiva del contenuto seguita da un video sperimentale per la discussione dell'argomento. Abbiamo scelto di utilizzare YouTube in quanto è

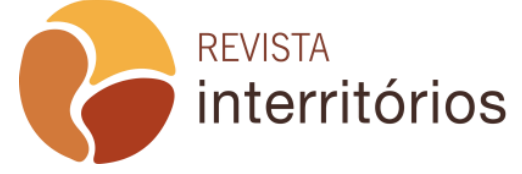

Interritórios | Revista de Educação Universidade Federal de Pernambuco, Caruaru, BRASIL | V.6 N.12 [2020] 
una delle piattaforme più visitate da qualsiasi studente. È stato scelto un video che conteneva un esperimento chiaro e oggettivo correlato ai contenuti sopra menzionati. Quindi è stato prodotto il video della lezione pratica, che conteneva una breve contestualizzazione nella vita quotidiana degli studenti, seguito dal video sperimentale di YouTube e infine da alcune domande discorsive. I risultati indicano che l'approccio video sperimentale ha un vantaggio significativo rispetto alle lezioni, rafforzando l'importanza dell'utilizzo di pratiche sperimentali aggiuntive in classe.

Insegnamento di chimica. Lezione pratica. Teoria dei gas. Termodinamica. Video sperimentale.

\section{INTRODUÇÃO}

A introdução da educação científica no Brasil teve início na década de 50 com o objetivo indispensável e urgente de formação de investigadores científicos e críticos, de maneira que este advento foi um dos fatores que impulsionou o avanço da ciência e tecnologia das quais dependia o progresso do país, que passava por um intenso processo de industrialização (KRASILCHIK, 2000; PONTES, et al, 2008). Porém, no decorrer das últimas décadas, a modernidade radicalizada pelo fenômeno da globalização vem impondo ao mundo diversas e profundas transformações (CACHAPUZ, et al; LIMA, 2016). E com isto, os educadores, especificamente os de ciências, têm se deparado com o seguinte obstáculo: encontrar meios que impactem positivamente os estudantes para aumentar o seu interesse nas aulas ministradas (DOS SANTOS, 2019). Sendo assim, alguns pesquisadores têm demonstrado que parte desta dificuldade vem pelo impedimento dos alunos em compreender os modelos e fórmulas essenciais para as ciências, uma vez que o este ensino trata de conceitos extremamente abstratos (MALAFAIA \& RODRIGUES, 2008; HONORIO, et al, 2006; DE LIMA, 2015).

Em termos práticos, tratando-se da física e química, o fracasso do processo de aprendizagem é um fato e não há quem o desconheça (POZZOBON, MAHENDRA, MARIN, 2017). Tradicionalmente, o ensino destas matérias na educação básica na maior parte das escolas públicas a nível nacional, se resume à apresentação de conteúdos pelo professor e a resolução de exercícios, sem a realização de práticas em laboratório ou o uso de tecnologias durante o processo de aprendizagem (DOS SANTOS, 2019; FIORENTINI, 2012). Os conceitos, leis e fórmulas em geral são ensinados de maneira completamente desarticulados e distanciados do mundo vivido pelos alunos e professores, o que torna tais conteúdos extremamente desinteressantes e acentuam ainda mais as dificuldades apresentadas, deixando estes ensinos calcados no tradicionalismo e em tendências mecanicistas (DE LIMA, 2012¹; DE LIMA, 2012²). Neste contexto, é fácil de se encontrar na literatura e mesmo na prática em sala de aula no dia a dia, a repulsa 
dos alunos por estas componentes curriculares (PONTES, et al, 2008; LIMA, 2016; DOS SANTOS, DICKMAN, 2019).

Em recente trabalho, Santos \& Dickman, 2019, destacam:

Segundo Fiolhais e Trindade (2003, p. 259) "entre as razões do insucesso na aprendizagem em física são apontados os métodos de ensino desajustados das teorias de aprendizagem, assim como a falta de meios pedagógicos modernos e atrativos". De acordo com Alves (2006, p. 11), a quase inexistência de equipamentos e atividades práticas/experimentais e as dificuldades metodológicas e didáticas dos professores, são fatores fundamentais para a aversão dos alunos a estas disciplinas. (SANTOS, DICKMAN, 2019, p 2).

Já para Rocha \& Vasconcelos, (2016) o ensino de química, igualmente ao que acontece em outras ciências exatas, segue ainda de maneira tradicional, de forma descontextualizada e não interdisciplinar, gerando nos alunos um grande desinteresse pela matéria, bem como dificuldades de aprender e de relacionar 0 conteúdo estudado ao cotidiano, mesmo a química e física estando presente na realidade vivida por eles e por todos nós.

Estes fatos vão contra as orientações das bases curriculares nacionais, sejam elas o Parâmetros Curriculares Nacionais (PCN+) (BRASIL, 1999) ou a Base Curricular Nacional Comum (BNCC) (MINISTÉRIO DA EDUCAÇÃO, 2019), onde o ensino de física e química deve deixar de concentrar-se na simples memorização de fórmulas ou repetição automatizada de procedimentos, em situações artificiais ou excessivamente abstratas, e devem apresentar um conjunto de competências específicas que proporcionem aos alunos o contato com processos, práticas e procedimentos da investigação científica para que sejam capazes de intervir de forma positiva na sociedade (DOS SANTOS, DICKMAN, 2019). Dentro dessa perspectiva, o estudo das ciências da natureza propõe possibilitar ao homem conhecer a si próprio, entender suas relações com os demais seres vivos e desvendar os fenômenos que se manifestam no meio ambiente. Enfim, abrir novas perspectivas para que possa viver com qualidade e dignidade, nesse mundo cada vez mais globalizado (DE LIMA, 2015; DA SILVA, NÚÑEZ, 2002).

Neste contexto, há mais de duas décadas vêm-se discutindo novas formas de trabalhar os conteúdos destas disciplinas, de maneira que novos paradigmas didáticos surgem como proposta de inovação para o ensino destas ciências de forma que os documentos normativos em suas normas e competências sejam obedecidos e complementados em salas de aula de todo o território nacional (DE LIMA, 2015). 
De acordo com Lima, 2015, sabe-se que as escolas públicas de todo o país, quando se trata da disciplina de física e química, não fazem uso de recursos didáticos externos à sala de aula, os quais poderiam proporcionar conhecimentos advindos de informações veiculadas, por exemplo, através de multimídias (DOS SANTOS, CAVALCANTI, 2016). Ao filtrar e incorporar esses materiais como subsídios, eles poderiam preencher as lacunas deixadas durante o desenvolvimento do processo de ensino e aprendizagem. As escolas em sua grande maioria utilizam apenas os recursos usuais comuns, como o livro didático e o quadro-de-giz e, dessa maneira, diminui as possibilidades de interesse, entendimento e assimilação dos conceitos físicos e químicos por parte dos alunos, os construtores ativos do próprio conhecimento (DA SILVA, 2002). Nesta perspectiva, a experimentação ocupou um papel essencial na consolidação das ciências a partir do século XVIII (QUEIROZ, DE ALMEIDA, 2004). Assim, têmse o conhecimento de que a física e química são ciências experimentais; o que torna difícil a sua aprendizagem sem a realização de atividades práticas (MALDANER, 1999; FARIAS, BASAGLIA, ZIMMERMANN, 2009). Desta forma, estas atividades devem possibilitar aos alunos o manuseio de equipamentos não comuns ao cotidiano da maioria dos alunos, como por exemplo, vidrarias de laboratório; observar e visualizar transformações de substâncias e fenômenos naturais; possibilitando a estes uma forma de criticar, compreender, interpretar e idealizar as abstrações adotas nas disciplinas de física e química em suas fórmulas e modelos teóricos, corroborando para a construção da sua reflexão crítica do mundo, além de um desenvolvimento cognitivo (MALDANER, 1999; FARIAS, BASAGLIA, ZIMMERMANN, 2009).

Russel, em 1994, afirmava que quanto mais integrada a aulas teóricas e a prática, mais sólida se torna a aprendizagem do ensino de ciências, pois ela cumpre sua verdadeira função dentro do ensino, contribuindo para a construção do conhecimento teórico, não de forma linear, mais transversal, ou seja, não apenas trabalha a teoria no cumprimento da sua sequência de conteúdo, mais interage o conteúdo com o mundo vivencial dos alunos de forma diversificada, associada à experimentação do dia-a-dia, aproveitando suas argumentações e indagações. Portanto, a atividade experimental em sala de aula, mesmo que seja uma demonstração experimental feita pelo professor, torna-se de suma importância. Com isto, apesar de todas as dificuldades e obstáculos, percebe-se a importância de incorporar atividades experimentais extras no ensino de física e química, propiciando além da motivação e interesse, momentos de discussão e reflexão, o que contribui para facilitar o aprendizado.

Entretanto, as implementações destas propostas fazem surgir a seguinte questão: "Atividades experimentais, realizadas em laboratório com equipamentos reais ou virtualmente, trazem, de fato, vantagens ao aprendizado dos alunos, quando comparadas com as aulas expositivas tradicionais"? Assim, estudos demonstram que realizações de pesquisas/aulas experimentais em 
salas de aula facilitam o processo ensino-aprendizagem, envolvem professor e aluno, formam cidadãos mais críticos, com perfil de pesquisador e enriquecem as habilidades profissionais (DOS SANTOS, DICKMAN, 2019; BRASIL, 1999; MINISTÉRIO DA EDUCAÇÃO, 2019; RUSSEL, 1994; DE SÁ, 2003).

Desta forma, neste trabalho é feito um estudo da aplicação de um destes recursos didáticos, um vídeo com conteúdo experimental, com o objetivo de se investigar se este contribui para o aprendizado dos alunos. Para tal, toma-se como base um experimento para a verificação do estudo cinético molecular dos gases, em específico a expansão livre e adiabática, assunto que faz parte da programação tanto de física e quanto de química do ensino médio da maioria das escolas brasileiras. A proposta aqui apresentada consiste, portanto, em aplicar uma abordagem experimental com o uso de um vídeo contextualizado, além de teórica (aulas ministradas), afim de comparar os dados entre as turmas, verificando o efeito na aprendizagem dos alunos. Para estes fins, utilizou-se o Youtube, que pode ser considerada uma das plataformas de maior acesso por todos os tipos de estudantes.

\section{Metodologia}

Neste trabalho foi elaborado um vídeo constituído da seguinte forma: uma breve contextualização do conteúdo da teoria cinética molecular dos gases e expansões adiabáticas ou livres, presentes no cotidiano dos alunos; seguida do experimento e por fim algumas perguntas discursivas sobre o assunto. Ressaltase que o vídeo do experimento foi retirado do Youtube, onde teve-se a preocupação de se escolher um vídeo claro, objetivo e que correspondesse com a teoria a ser abordada nas aulas teóricas. Além disso, teve-se o cuidado de retirar o vídeo de um canal didático para que não houvesse assimilação de conceitos errôneos. O vídeo foi retirado do canal Física Universitária que tem como coordenador o Prof. Mr. Cláudio Hiroyuki Furukawa, professor do Instituto de Física da Universidade de São Paulo - USP Com isto, o vídeo 4 resultante do processo aqui descrito, denominado de vídeo experimental, teve como intuito/objetivo ser utilizado como um roteiro de "aula prática".

Para o começo das análises referentes a este trabalho, escolheu-se as turmas nas quais os alunos seriam avaliados através dos questionários adotados por este trabalho (exercícios de aprendizagem + questionário no final do vídeo experimental), sendo estas duas turmas de ensino médio, duas do segundo e duas do terceiro ano, de uma escola de rede particular do interior de Minas Gerais. A Tabela 1 mostra as terminologias utilizadas para cada turma além de suas respectivas quantidades de alunos.

\footnotetext{
${ }^{4}$ https://www.youtube.com /watch?v=vhTrMeqJ5ro\&. 
Tabela 1 - Distribuição do número de alunos pelas turmas e suas respectivas terminologias. ${ }^{5}$

\begin{tabular}{c|c|c|c|c}
\hline Turma & 20 $\mathbf{L}$ & 20 V & 3 $\mathbf{L}^{-}$ & 3ㅇ V \\
\hline Número de alunos & 21 & 18 & 13 & 17 \\
\hline
\end{tabular}

Fonte: autor.

Inicialmente buscou-se avaliar se as atividades experimentais têm melhor efeito sobre a aprendizagem dos alunos quando comparadas apenas com aulas expositivas tradicionais. Optou-se pelo tema leis da teoria cinética molecular dos gases e termodinâmica por serem tópicos que fazem parte da programação de física e química, no primeiro, segundo e terceiro ano do ensino médio da escola mencionada. Além disso, a apresentação desses assuntos coincidiu com a programação da unidade escolar de um dos autores deste trabalho, permitindo a aplicação das atividades durante as aulas de química, sem necessitar que os alunos viessem fora do seu horário normal de aulas. Este fato permite trabalhar mais próximo da situação real e todos os alunos das turmas mencionadas participaram da pesquisa, ou seja, o universo da pesquisa abrangeu alunos com interesses diversificados em relação ao componente curricular.

\section{Abordagem de ensino}

Foram ministradas aulas expositivas (4 aulas de cinquenta minutos) do conteúdo a ser abordado no vídeo experimental. Em seguida, em duas aulas subsequentes, aplicou-se um exercício de aprendizagem com oito questões para a avaliação de assimilação pelos alunos. Por fim, os alunos foram orientados a assistir o vídeo experimental para responder ao questionário contido no final do vídeo, totalizando uma avalição com 16 questões -8 antes e 8 pós vídeo. Os alunos foram informados de que toda orientação referente à atividade experimental do vídeo estaria no roteiro distribuído no início das aulas de química mencionadas.

Instrumentação para avaliação

O critério de validação da participação dos alunos no estudo aqui proposto se deu da seguinte forma: o aluno que fosse participar deste processo de análise

${ }^{5}$ Os termos L e V são os adotados pelo Instituto Maria Augusta Machado para diferenciar a duas turmas de mesmo grau de ensino. 
deveria ter frequentado no mínimo $60 \%$ das aulas relacionadas a este estudo; além de ter respondido a todas as questões dos exercícios de aprendizagem e do questionário contido no final do vídeo experimental. Para a elaboração dos exercícios de aprendizagem foram utilizados os livros didáticos do segundo e terceiro ano adotados pela escola. Já para as questões utilizadas no final do questionário do vídeo (tabela 2), utilizou-se como referência um roteiro de aula prática aplicado por um dos autores nas aulas práticas de física da Universidade Estadual de Minas Gerais, UEMG campus Divinópolis, sendo que algumas adaptações foram realizadas para contemplar o nível dos estudantes aqui em análise.

Tabela 2 - Perguntas contidas na adaptação do questionário da UEMG para avaliação do efeito de aprendizagem dos alunos após vídeo experimental

\begin{tabular}{|c|c|}
\hline Questão & Pergunta \\
\hline 01 & Quais foram as temperaturas observadas no vídeo? \\
\hline 02 & $\begin{array}{l}\text { Tente descrever o que causa o aumento de temperatura } \\
\text { ao se bombear ar para dentro da garrafa. }\end{array}$ \\
\hline 03 & $\begin{array}{l}\text { O que foi observado no termômetro depois de } \\
\text { transcorridos alguns minutos? }\end{array}$ \\
\hline 04 & $\begin{array}{c}\text { Com o PET cheio foi retirado o tampão bruscamente, } \\
\text { assim tente descrever o que se observa. A temperatura no interior } \\
\text { da garrafa continua a mesma? }\end{array}$ \\
\hline 05 & $\begin{array}{l}\text { Use a primeira lei da termodinâmica e a teoria cinética dos } \\
\text { gases para descrever os motivos físicos da sua observação, ou } \\
\text { seja, o que causa o efeito observado? Isto seria uma expansão } \\
\text { livre ou uma expansão adiabática? }\end{array}$ \\
\hline 06 & $\begin{array}{c}\text { O que se observa ao bombear ar novamente para dentro } \\
\text { da garrafa preenchida com névoa? Descreva a causa do } \\
\text { fenômeno observado. }\end{array}$ \\
\hline 07 & $\begin{array}{l}\text { Por que a substância contida dentro do botijão de cozinha } \\
\text { está líquida e quando a válvula é aberta ela se torna gás? }\end{array}$ \\
\hline 08 & $\begin{array}{l}\text { Como você julga que é feito o preenchimento do botijão de } \\
\text { gás? A temperatura é sempre a mesma ou ela é mantida } \\
\text { constante? }\end{array}$ \\
\hline
\end{tabular}

Fonte: autor.

O teste consistiu de dezesseis questões ao total; sendo que oito delas foram questões discursivas de vestibulares e presentes nos livros didáticos para a avaliação de assimilação do conteúdo (RAGAZZI, 2020; GUERRA, PAULA, 
RAGAZZI; 2020); e as outras oito questões restantes foram dissertativas sobre as características e observações feitas durante o vídeo experimental de compressão adiabática. As questões podem ser classificadas de acordo com as respectivas competências e habilidades requeridas do aluno em cada uma delas, com base nos PCN+ Ensino Médio (BRASIL, 1999) e BNCC (MINISTÉRIO DA EDUCAÇÃO, 2019). Optou-se por escolher uma competência a ser avaliada para cada questão, mesmo havendo a possibilidade de avaliação de mais competências.

Assim, em todas a questões dos dois questionários adotados, ao analisar as variações de temperatura, de volume, pressão, trabalho e entre outras propriedades química e físicas, permitiria ao aluno a identificação de fenômenos naturais ou grandezas em um dado domínio do conhecimento científico e o estabelecimento de relações; identificação de regularidades, invariantes e transformações, além do reconhecimento da conservação de determinadas grandezas, como massa, energia cinética; identificar formas de dissipação de energia e limitações quanto aos tipos de transformações possíveis, impostas pela existência, na natureza, de processos irreversíveis. Finalmente, todas as questões, solicitam que os alunos interpretem determinadas características e relatem o processo, busquem desenvolver competências e habilidades relacionadas à elaboração de comunicações escritas para relatar, analisar e sistematizar eventos, fenômenos, experimentos, correspondências, bem como a elaboração de relatórios analíticos, apresentando e discutindo dados e resultados, seja de experimentos ou de avaliações críticas de situações, fazendo uso, sempre que necessário, da linguagem física e química apropriada (BRASIL, 1999; MINISTÉRIO DA EDUCAÇÃO, 2019).

A correção dos questionários foi feita atribuindo para cada um dos itens uma nota na escala de 0 a 5 , onde 0 é totalmente inconsistente e 5 é totalmente consistente com a explicação cientificamente aceita. Desta forma, o aluno poderia totalizar no máximo 5 pontos. Assim, as notas foram normalizadas para uma escala de 0 a $100 \%$.

Avaliação dos alunos quanto a metodologia utilizada

Para se ter um conhecimento de preferências/satisfação dos alunos quanto a metodologia utilizada, aplicou-se um questionário de oito questões, sendo 5 objetivas de atribuição de notas ao vídeo experimental, e as demais 3 questões discursivas para a exposição de opiniões quanto a metodologia abordada, conforme ilustrado pela tabela 3 . 
Tabela 3 - Perguntas contidas no questionário de satisfação para avaliação dos alunos quanto à proposta de adoção de vídeos experimentais

\begin{tabular}{c|l}
\hline Item & \multicolumn{1}{c}{ Questão } \\
\hline A & $\begin{array}{l}\text { Contribuição do vídeo para o entendimento dos objetivos e resultados } \\
\text { experimentais. }\end{array}$ \\
\hline B & $\begin{array}{l}\text { Você se sentiu mais motivado ao conhecer a aplicação deste } \\
\text { assunto/experimento no seu cotidiano como aluno? }\end{array}$ \\
\hline C & Qualidade do vídeo. \\
\hline D & Após o vídeo você seria capaz de realizar o experimento sozinho? \\
\hline E & $\begin{array}{l}\text { Você recomenda este método de ensino em outras aulas práticas } \\
\text { futuras? }\end{array}$ \\
\hline
\end{tabular}

Fonte: autor.

\section{Resultados e discussões}

A Figura 1 mostra o aproveitamento médio das turmas nas questões do exercício de aprendizagem antes da exposição do vídeo para os alunos.

Figura 1 - Porcentagem de aproveitamento por questão do exercício de aprendizagem para o 2 e 3 ano do ensino médio

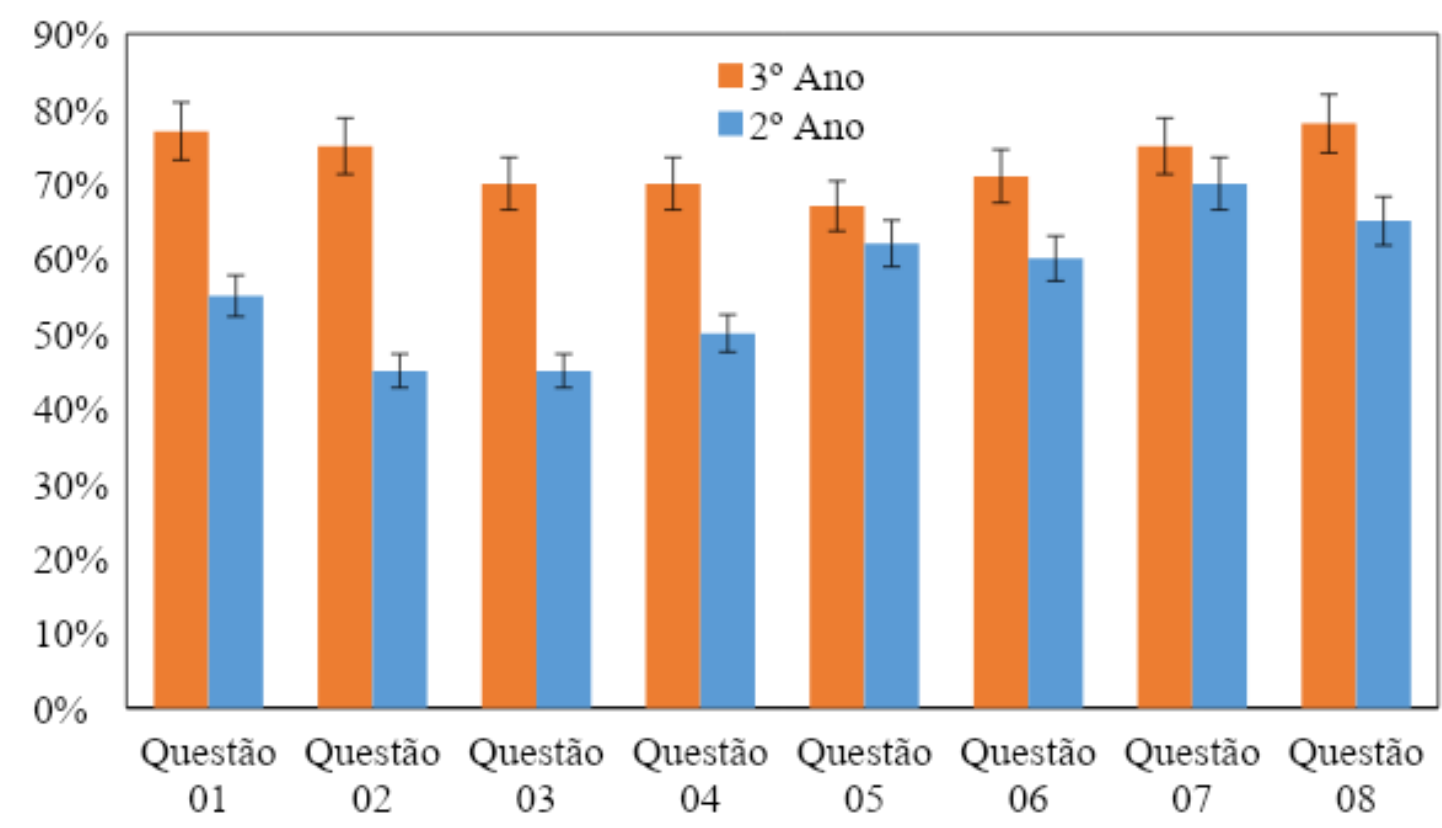

Fonte: autor. 
Observa-se que a turma do $3^{\circ}$ ano apresentou um desempenho superior ao do $2^{\circ}$ ano em todas as questões. Supõe-se que isto se deve à maior bagagem de conhecimento do $3^{\circ}$ ano, uma vez que turma já teve contato com o assunto no ano anterior. Ainda para o terceiro ano, é importante destacar que a maioria dos alunos apresentou rendimento superior a $70 \%$. Observou-se durante a aplicação do teste que houve um maior comprometimento por parte dos alunos do $3^{\circ}$ ano, sendo que alguns relataram a preocupação com o vestibular.

Com relação ao aproveitamento dos alunos após a exposição do vídeo, observa-se uma melhoria significativa (Figura 2). Ambas as turmas apresentaram rendimento superior a $60 \%$ em todas as questões. No caso do $3^{\circ}$ ano, as notas médias foram de $75 \%$ para os exercícios de aprendizagem e $80 \%$ para a avaliação após o vídeo experimental. Esse resultado poderia ser atribuído ao fato de que o conteúdo foi novamente visto pelos alunos na abordagem experimental, e que esta repetição por si só reforçaria o aprendizado. Para o $2^{\circ}$ ano, observa-se um aumento do rendimento médio de $45 \%$ para $65 \%$.

Figura 2 - Aproveitamento por questão do exercício de aprendizagem para efeito de comparação das turmas de $3^{\circ}$ e $2^{\circ}$ ano do ensino médio

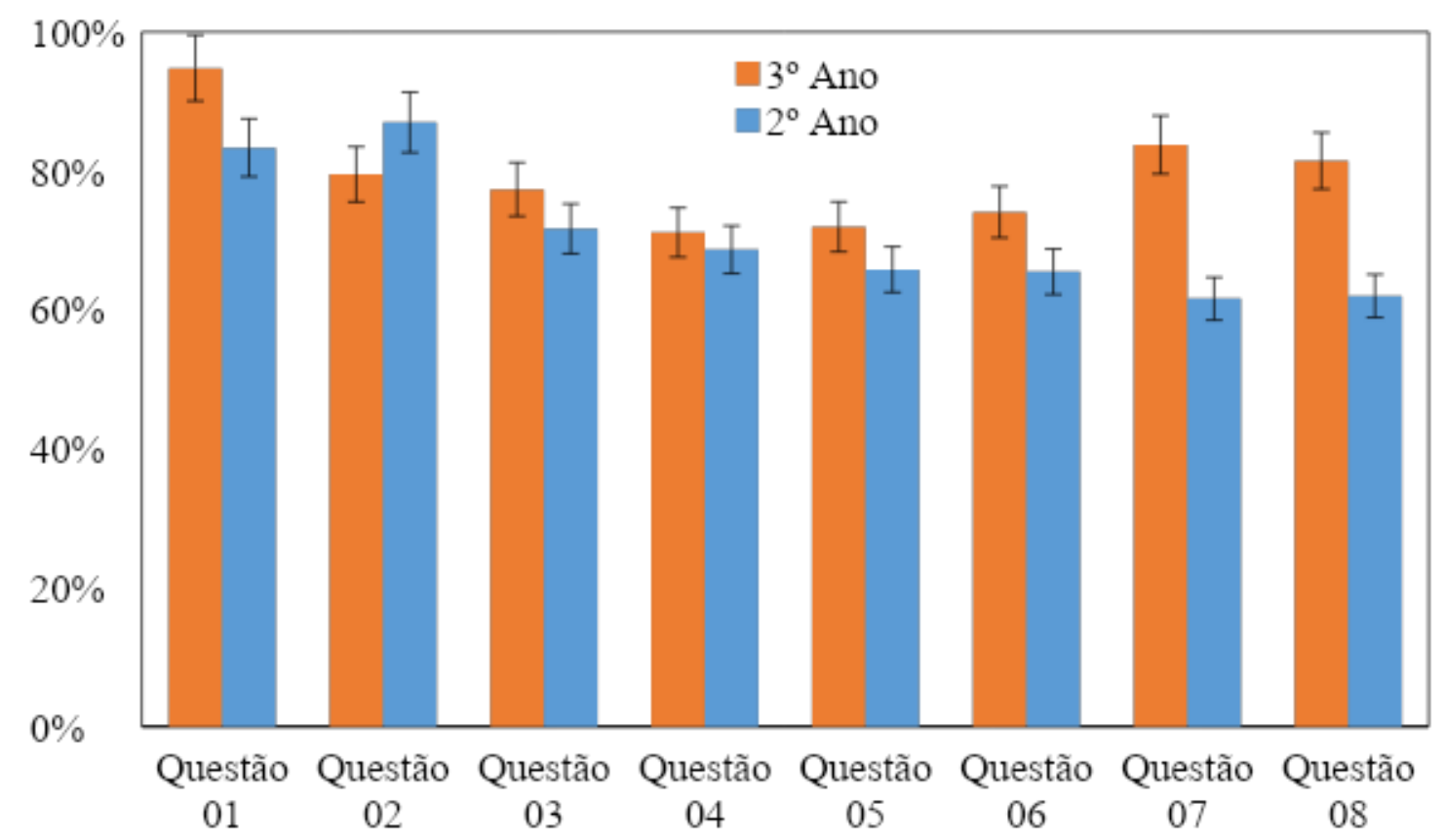

Fonte: autor.

Vale ressaltar que as questões de caráter interdisciplinar, menos mecanicistas e de repetição de conteúdo, foram aquelas com menor aproveitamento. Isto está em acordo com resultados observados na literatura (KRASILCHIK, 2000; PONTES, et al, 2008; CACHAPUZ, et al, 2011; LIMA, 2016; DOS SANTOS \& DICKMAN, 2019). 
Para avaliar o nível de satisfação e aprovação da metodologia por parte dos alunos (Tabela 3), procedeu-se com a análise da Figura 3, onde 100\% corresponde à completa aprovação as perguntas feitas do vídeo.

Figura 3 - Porcentagem de avaliação por alunos para a adoção de vídeo experimental para aulas experimentais de química e física

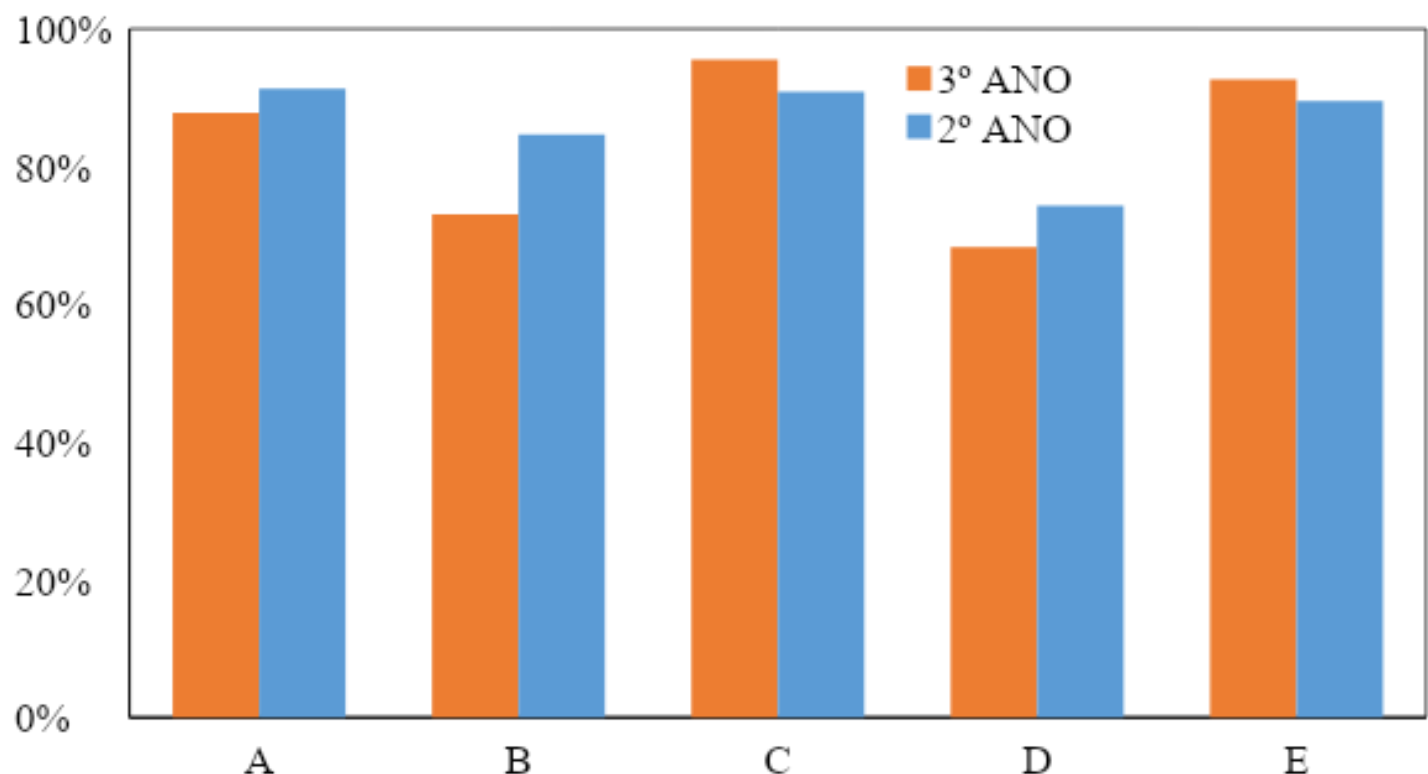

Fonte: autor.

No geral, observa-se que todos os alunos de ambas as turmas aprovaram a ideia da introdução da metodologia aqui proposta, uma vez que a porcentagem de avaliação em relação ao vídeo ficou sempre acima de $70 \%$. A avalição ficou acima de $80 \%$ para a ideia de adoção do vídeo experimental em aulas de química e física com conteúdo mais complexos, item A. Para a motivação em compreender melhor o conteúdo abordado após assistir o vídeo, a taxa de avaliação ficou em $70 \%$, item B. Para o item C, foi avaliado a qualidade do vídeo que teve uma média de aceitação de $90 \%$. No entanto, quando se trata da reprodutibilidade do experimento no vídeo, a taxa de avaliação fica com a pior média, um pouco abaixo de $70 \%$ e exatamente $70 \%$ para o segundo e terceiro ano, respectivamente. Este fato pode ser atribuído a atividade experimental ter sido realizado por vídeo, o que compromete o entendimento de questões básicas da montagem do experimento, como o encaixe correto da rolha na garrafa pet, qual termômetro utilizar, a troca do compressor manual por outro equipamento de maior acesso, dentre outros. E no geral, a taxa de recomendação do vídeo, item E, está na faixa de $90 \%$. Tais observações levantadas pelos alunos são de suma importância, uma vez que contribuem para avaliar o seu comprometimento com as aulas e atividades propostas, além de aguçar a sua atenção para algo 
diferenciado do seu cotidiano, o que acaba tornando uma estratégia didática de suma importância paras o professor de química e física. Destaca-se ainda que este tipo de abordagem com o uso de vídeo experimental pode ser utilizado por professores que não tem acesso a dispositivos de laboratório para 0 desenvolvimento de aulas práticas. $\mathrm{E}$ assim, com base nos trabalhos feitos com os alunos e com os resultados obtidos, as atividades experimentais são bastante proveitosas. Verifica-se que a maioria dos alunos gostam de participar dessas atividades, despertando assim, o seu interesse pela física e química. Esta consideração está em acordo com os diversos estudos da literatura (DOS SANTOS \& DICKMAN, 2019; MALAFIA \& RODRIGUES, 2008; HONORIO, et al, 2006; DE LIMA, 2012 a; DE LIMA, 2012 b.

\section{CONCLUSÃO}

Este trabalho corroborou que 0 uso de vídeos sobre práticas experimentais promove uma melhoria no processo ensino-aprendizagem. O que só reforça a importância deste tipo de atividades didáticas no ensino de química e física, principalmente quando comparadas com as aulas expositivas tradicionais. Os resultados mostraram que a abordagem utilizada foi proveitosa para os alunos, tanto na assimilação e contextualização do conteúdo quanto na sua motivação e interesse pelas aulas. No entanto, têm-se como desvantagem o fato de os alunos não terem manuseado os equipamentos mostrados no vídeo. Porém é conveniente ressaltar que os usos de abordagens como a proposta por este trabalho possuem como vantagens a simplicidade e a facilidade de utilização pelos professores. Ainda, destaca-se que este tipo de abordagem pode der se suma importância para alguns professores, uma vez que a maioria das escolas dos ensinos públicos não possuem laboratório.

\section{AGRADECIMENTOS}

Ao Instituto Maria Augusta Machado - IMAM e alunos pelo apoio a pesquisa deste trabalho. Ao Prof. Mr. Cláudio Hiroyuki Furukawa, professor do Instituto de Física da Universidade de São Paulo - USP por permitir o uso do vídeo do canal didático do Youtube em que faz parte.

\section{REFERÊNCIAS}

ALVES, Valéria de Freitas. A inserção de atividades experimentais no ensino de física em nível médio: em busca de melhores resultados de aprendizagem [Dissertação de mestrado]. Brasília: Ensino de Ciências da UnB. 2006. Disponível em: http://ppgec.unb.br/wp-content/uploads/dissertacoes/2006/2006_ValeriaAlves.pdf. 
ALVES, Wanderson Ferreira. A formação de professores e as teorias do saber docente: contexto, dúvidas e desafios. Revista Educação e Pesquisa. 2007, v. 33: p. 263-280. Disponível em: https://www.scielo.br/pdf/ep/v33n2/a06v33n2.pdf.

BRASIL. PCN+ Ensino Médio: Orientações Educacionais complementares aos Parâmetros Curriculares Nacionais, 1999. Disponível em:

http://portal.mec.gov.br/seb/arquivos/pdf/CienciasNatureza.pdf.

CACHAPUZ, Antonio. et al. A necessária renovação do ensino das ciências. 3 ed. São Paulo: Cortez, 2011.

FARIAS, Cristiane Sampaio; BASAGLIA, Andréia Montani; ZIMMERMANN, Alberto. A importância das atividades experimentais no Ensino de Química. 1 Congresso

Paranaense de Educação em Química. In: Anais do 1 1ํㅡㄹ Congresso Paranaense de Educação em Química. Londrina, UEL. 2009. Disponível em: http://www.uel.br/eventos/cpequi/Completospagina/18274953820090622.pdf.

FIOLHAIS, Carlos; TRINDADE, Jorge. Física no computador: o computador como uma ferramenta no ensino e na aprendizagem das ciências físicas. Revista Brasileira de Ensino de Física. 2003, v. 25: p. 259-272. Disponível em: https://www.scielo.br/pdf/rbef/v25n3/a02v25n3.pdf.

FIORENTINI, Dario; LORENZATO, Sergio. Investigação em educação matemática percursos teóricos e metodológicos. $3^{\text {a }}$ ed. São Paulo: Autores Associados, 2012. GUERRA, Fabiano; PAULA, Ívina; RAGAZZIde , Marcos. Coleção 4V: Manual do Professor. Belo Horizonte: Bernoulli Sistema de Ensino, 2020.

HONORIO, Kathia Maria. et al. O show da Química: motivando o interesse científico. Química Nova. 2006, v. 29: p. 173-178. Disponível em:

http://static.sites.sbq.org.br/quimicanova.sbq.org.br/pdf/Vol29No1_173_30ED04399.pdf.

KRASILCHIK, Myriam. Reformas e realidade o caso do ensino das ciências. São Paulo em Perspectiva. 2000, v. 14: p. 85-93. Disponível em:

https://www.scielo.br/pdf/spp/v14n1/9805.pdf.

LIMA, José Ossian Gadelha. $O$ ensino da química na escola básica: o que se tem na prática, o que quer em teoria. Ensino de Ciências e Tecnologia em Revista. 2016, v. 6. Disponível: http://dx.doi.org/10.20912/2237-4450/2016.v6i2.1245.

LIMA, José Ossian Gadelha de a. O ensino de química na concepção dos alunos do ensino fundamental: algumas reflexões. Revista Científica do Departamento de Química Exatas. 2015., v. 6: p. 33-48. Disponível em:

https://www.researchgate.net/publication/274633453_o_ensino_de_quimica_na_conc epcao_dos_alunos_do_ensino_fundamental_algumas_reflexoes.

LIMA, José Ossian Gadelha de b . Perspectivas de novas metodologias no Ensino de Química. Revista Espaço Acadêmico. 2012, v. 12: p. 95-101. Disponível em: http://periodicos.uem.br/ojs/index.php/EspacoAcademico/article/view/15092. ${ }^{1}$

LIMA, José Ossian Gadelha; LEITE, Luciana Rodrigues . O processo de ensino e aprendizagem da disciplina de Química: o caso das escolas do ensino médio de Crateús/Ceará/Brasil. Revista Electrónica de Investigación em Educación en

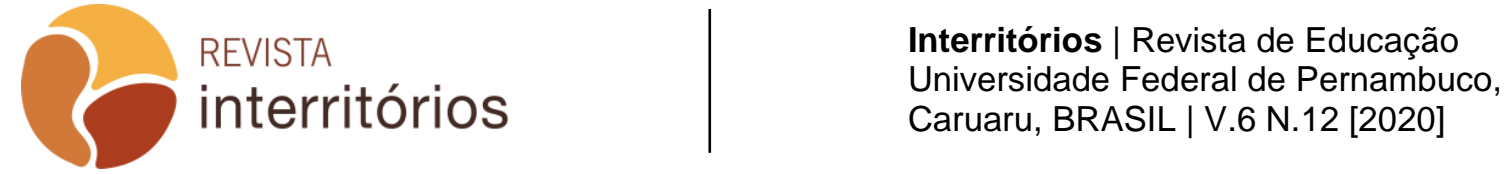


Ciencias. 2012, v. 7: p. 72-85. Disponível em:

http://ppct.caicyt.gov.ar/index.php/reiec/article/view/7485.

MALAFAIA, Guilhere; RODRIGUES, Aline Sueli de Lima. Uma reflexão sobre o ensino de ciências no nível fundamental da educação. Ciência \& Ensino. 2008, v. 2: p: 01-09.

MALDANER, Otavio Aloisio. A pesquisa como perspectiva de formação continuada do professor de química. Química Nova. 1999, v. 22: p. 289-292. Disponível em:

http://static.sites.sbq.org.br/quimicanova.sbq.org.br/pdf/Vol22No2_289_v22_n2_20\%2 822\%29.pdf.

MINISTÉRIO DA EDUCAÇÃO; Base nacional curricular comum - Educação é a base. 2019. Disponível em:

http://basenacionalcomum.mec.gov.br/images/BNCC_EI_EF_110518_versaofinal_site. pdf.

NARDI, Roberto. Questões Atuais no Ensino de Ciências. São Paulo: Escrituras, 1998.

PONTES, A. N. et al. O ensino de química no nível médio: um olhar a respeito da motivação. In: XIV Encontro Nacional de Ensino de Química, Curitiba, 21 - 24 jul. 2008. Anais do XIV Encontro Nacional de Ensino de Química. Curitiba: UFPR, 2008. Disponível em:

https://drive.google.com/file/d/1omolxa56fcjqY6nEC_kc25dpKZRPdO5Q/view.

POZZOBON, Magda; MAHENDRA, Fénita; MARIN, Angela Helena. Renomeando o fracasso escolar. Piscologia Escolar e Educacional. 2017, v. 21: p. 387-396.

Disponível em: https://www.scielo.br/pdf/pee/v21n3/2175-3539-pee-21-03-387.pdf.

QUEIROZ, Salete Linhares; DE ALMEIDA, Maria José Pereira Monteiro. Do fazer ao compreender ciências: reflexões sobre o aprendizado de alunos de iniciação científica em química. Ciência \& Educação. 2004, v. 10: p. 41-53. Disponível em: ttp://dx.doi.org/10.1590/S1516-73132004000100003.

RAGAZZI, Marcos. Coleção Ensino Médio 2a Série: Manual do Professor. Belo Horizonte: Bernoulli Sistema de Ensino, 2020.

ROCHA, Joselayne Silva; VASCONCELOS, Tatiana Cristina. Dificuldades de aprendizagem no ensino de química: algumas reflexões. In: XVIII Encontro Nacional de Ensino de Química (XVIII ENEQ). Anais do XVIII Encontro Nacional de Ensino de Química (XVIII ENEQ). Florianópolis: XVIII ENEQ, 2016. Disponível em: http://www.eneq2016.ufsc.br/anais/resumos/R0145-2.pdf.

RUSSELL, John B. Química Geral. 2. ed. São Paulo, 1994.

SÁ, Elaine Ferreira de. Os propósitos de atividades experimentais na visão de alunos e professores [Dissertação de mestrado]. Belo Horizonte: Edução da UFMG. 2003. Disponível em: https://repositorio.ufmg.br/bitstream/1843/EJRA-

5SFJ63/1/disserta_o_eliane_maio2005.pdf. 
SANTOS, José Carlos dos; DICKMAN, Adriana Gomes. Experimentos reais e virtuais: proposta para o ensino de eletricidade no nível médio. Revista Brasileira de Ensino de Física. 2019, v. 41. Disponível em: http://dx.doi.org/10.1590/1806-9126RBEF-2018-0161.

SANTOS Marcelo Ribeiro dos, CAVALCANTI Eduardo Luiz Dias Formação inicial e continuada dos professores de química: uma análise do quadro docente de Barreiras - Bahia. Orbital: The Electronic Journal of Chemistry. 2016, v. 8. Disponível em: http://www.orbital.ufms.br/index.php/Chemistry/article/view/710.

SILVA, Sebastião Franco da; NÚÑEZ, Isauro Beltrán. 0 ensino por problemas e trabalho experimental dos estudantes - Reflexões teórico-metodológicas. Química Nova. 2002, v. 25: p. 1197-1203. Disponível em: http://static.sites.sbq.org.br/quimicanova.sbq.org.br/pdf/Vol25No6B_1197_22.pdf. 